\title{
Moving knowledge across distance to improve healthcare - How telemedicine was used to improve maternal healthcare in bonsaaso cluster of amansie south district of Ghana
}

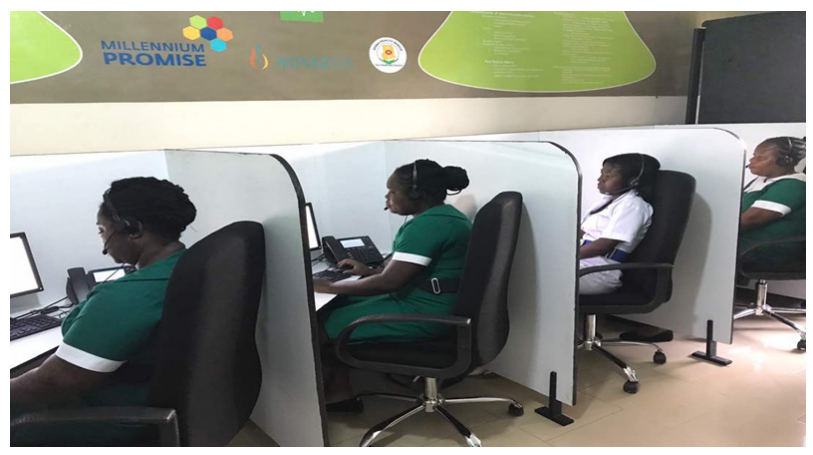

TeleConsultattion Center (TCC) Nurses at work

\section{Introduction}

In many developing countries there is an acute shortage of trained medical specialists and this hampers individual patient's access to medical diagnostics. Telemedicine has proven to have the capacity to revolutionize the delivery of healthcare. It supports efforts to significantly improve the quality, increase accessibility and efficiency of healthcare by reducing the need to travel whilst transferring expert knowledge. Telemedicine helps to remotely provide clinical support, overcoming geographic barriers and improving patient outcomes. Thus, telemedicine is an attractive tool to use for success in lower resource settings (Telemedicine and its Role in Revolutionizing Healthcare Delivery, Maryam Alvandi, DHS, MHS March 2017). Sub-Saharan Africa has almost been left behind the rest of the world in terms of development going through decades. Sub-Saharan Africa, made up of 33 of the 48 global poorest countries has to extend its ICT diffusion and policy to match the ever developing global economy. ${ }^{1-3}$

\section{Background}

In 2006 Millennium Promise Alliance (MPA) launched the Millennium Villages Project (MVP) in the Bonsaaso Cluster of Amansie West District (currently Amansie South District), Ghana as proof of concept for the attainment of United Nations Millennium Develoment Goals (MDGs). The cluster had 30 communities, 35000 population and 7,500 households. Majority of the people were smallholder farmers and small-scale traders. The challenges of the cluster included; inadequate access to health care; poor road network; high child and maternal mortality; high disease burden (Malaria, RTIs, HIV, Malnutrition etc) and limited number of human resource in the medical field. There was therefore the need to come up with an innovation that would bridge the accessibility gap (Figure 1).

The Telemedicine project was designed to move knowledge across distances by experienced physicians, nurses and midwives to peripheral healthcare providers using technology rather than moving
Volume 10 Issue 2 - 202I

Nathaniel Ebo Nsarko, Eric Akosah, Joseph
Sakyi Baah, John Eliasu Mahama
Millennium Promise Alliance, Ghana

Correspondence: Chief Nathaniel Ebo Nsarko, Executive Directors, Millennium Promise Allaiance, Ghana, Tel +2332446 I3246,

Email Chief.Nat-Nsarko@millenniumpromise.org

Received: December 18, 2020 | Published: April 12, 202 I the patient. The purpose was to design a simple Telemedicine system that would fit into Ghana's existing primary healthcare concept and a system that could easily be adapted and scaled. The conceptual design of the Ghana Telemedicine Project took place from 2007, jointly by the Earth Institute at Columbia University with Millennium Promise Alliance, Ghana's Ministry of Health (MOH) and Ghana Health Service (GHS) with financial and technical support from Novartis Foundation and Medgate respectively. ${ }^{4-6}$
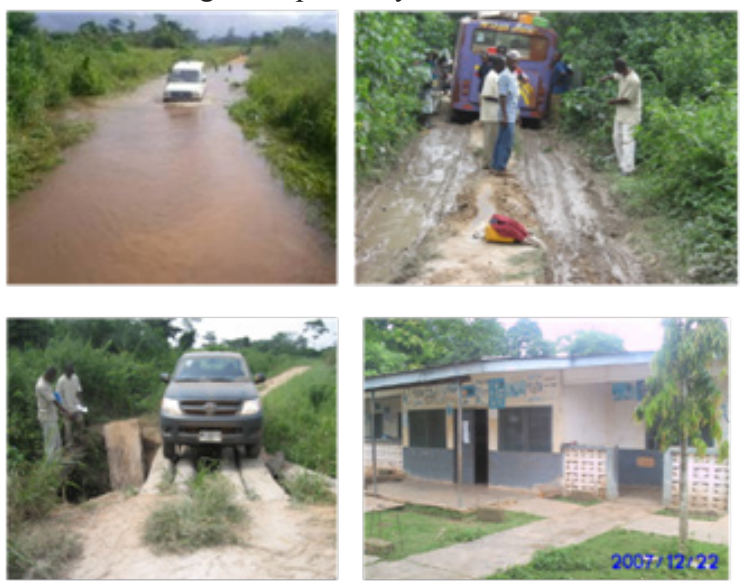

Figure I Pictures show poor roads, transportation challenges and one of the old health facilities in the periphery.

\section{Goal}

The main goal of establishing the Telemedicine Program was to reduce maternal and child mortalities. 


\section{Specific objectives}

a. Reduce high maternal and neonatal morbidities and mortalities.

b. Reduce unnecessary referrals.

c. Build capacity of peripheral healthcare providers through remote coaching via phone.

d. Provide prompt and efficient evacuation of referred clients to referral facility

\section{Conceptual frame of the Ghana telemedicine}

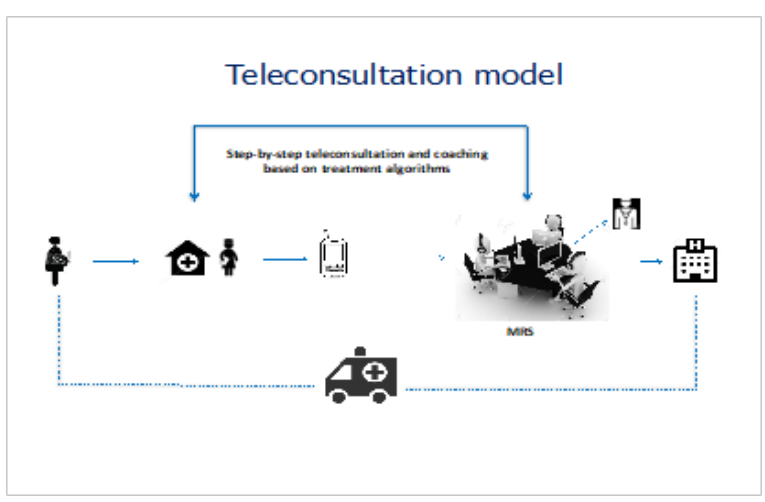

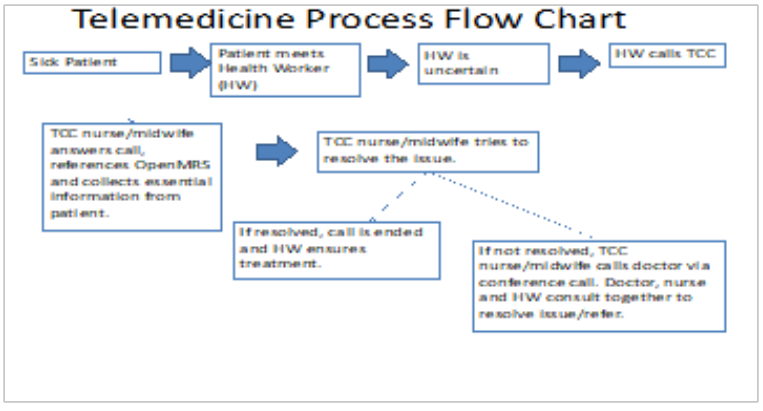

\section{Results}

Poor roads in the Amansie area made it difficult to refer patients in critical condition from a lower to higher facility. Introduction of Telemedicine in the Amansie West / South district brought a lot relieve to health workers at the peripheries since they could call to discuss their challenges in relation to patient's care for support. Table one shows that a total of $1224(72.3 \%)$ of the cases were either managed and resolved by TCC nurses or referred directly to the hospital while $27.7 \%$ of the calls were conferenced to a doctor for additional support (Figure 2).
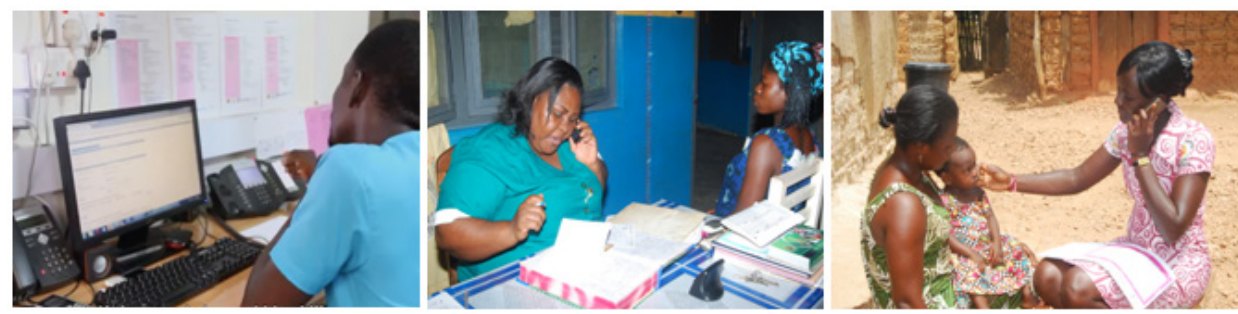

Figure 2 Picture showing TCC staff receiving call, a midwife attending to a pregnant woman and Community Health Officer in a home visit attending a child and calling TCC for additional support.

Table I Calls that pass through the TCC by Nurses and other health workers at periphery would be either managed and resolved by experienced TCC nurses or referred to the doctor on phone

\begin{tabular}{|c|c|c|c|c|c|c|c|}
\hline Patients TCC Served - Referrals & 2012 & 2013 & 2014 & 2015 & 2016 & 2017 & Total \\
\hline \# of patients TCC referred to doctor on phone & $115(51.6 \%)$ & $46(24.1 \%)$ & $71(31.3 \%)$ & $126(22.3 \%)$ & $66(16.9)$ & $44(45.8)$ & $468(27.7 \%)$ \\
\hline $\begin{array}{l}\text { \# of patients TCC Managed and did not refer } \\
\text { to doctor }\end{array}$ & $408(48.4 \%)$ & $145(75.9 \%)$ & $156(68.7 \%)$ & $438(77.7 \%)$ & $325(83.1 \%)$ & $52(54.2 \%)$ & $1224(72.3 \%)$ \\
\hline \# of Total Patients served & 223 & 191 & 227 & 564 & 391 & 96 & 1692 \\
\hline
\end{tabular}

Table 2 lindicates that from 2012 to 2017 , total of patients served under teleconsultation were I,692. About of third (32.8\%) of the patients were maternal health cases whilst $25.1 \%$ were child health related cases thereby contributing to reduction in maternal and child mortality.

\begin{tabular}{llllllll}
\hline $\begin{array}{l}\text { Patients Served by Disease/Cases } \\
\text { Category }\end{array}$ & $\mathbf{2 0 I 2}$ & $\mathbf{2 0 1 3}$ & $\mathbf{2 0 I 4}$ & $\mathbf{2 0 1 5}$ & $\mathbf{2 0 1 6}$ & 2017 & Total \\
\hline Maternal health & $60(28.3 \%)$ & $57(24.9 \%)$ & $71(31.4 \%)$ & $192(33.5 \%)$ & $142(37.2 \%)$ & $33(47.1 \%)$ & $555(32.8 \%)$ \\
Child health (U5) & $58(27.4 \%)$ & $77(33.6 \%)$ & $67(29.6 \%)$ & $128(22.3 \%)$ & $72(18.8 \%)$ & $22(31.4 \%)$ & $424(25.1 \%)$ \\
Infectious diseases & $7(3.3 \%)$ & $1(0.4 \%)$ & $1(0.4 \%)$ & $8(1.4 \%)$ & $7(1.8 \%)$ & $0(0.0 \%)$ & $24(1.4 \%)$ \\
Malaria & $38(17.9 \%)$ & $25(10.9 \%)$ & $29(12.8 \%)$ & $49(806 \%)$ & $40(10.5 \%)$ & $6(8.6 \%)$ & $187(11.1 \%)$ \\
NCD & $19(9.0 \%)$ & $17(7.4 \%)$ & $17(7.5 \%)$ & $31(5.4 \%)$ & $19(5.0 \%)$ & $5(7.1 \%)$ & $108(6.4 \%)$ \\
Other cases & $30(14.2 \%)$ & $52(22.7 \%)$ & $41(18.1 \%)$ & $165(28.8 \%)$ & $102(26.7 \%)$ & $4(5.7 \%)$ & $394(23.3 \%)$ \\
Total & $212(100 \%)$ & $229(100 \%)$ & $226(100 \%)$ & $573(100.0 \%)$ & $382(100.0 \%)$ & $70(100.0 \%)$ & $1692(100.0 \%)$ \\
\hline
\end{tabular}


Table 3 Out of the total number of maternal health cases that passed through the TCC, I02 (I8.4\%) were critical labour cases that TCC and Doctors supported periphery health workers performed successful deliveries (these were mainly retained placenta, $\mathrm{PHH}$, breech and others)

\begin{tabular}{llllllll}
\hline Patients Served-labour/Delivered on Cal & 2012 & 2013 & 2014 & 2015 & 2016 & 2017 & Total \\
\hline Critical labour Cases \& Babies Delivered on Call & 10 & 25 & 9 & 35 & 21 & 2 & 102 \\
\hline
\end{tabular}

\section{Conclusion}

Establishment of TeleConsultation Center (TCC) in the Amansie West/South helped to reduce maternal and child mortality drastically within the project area. Nurses, midwives and other health workers in the hard-to-reach area improved the professional skills through coaching on the phone. Ghana health service has adopted Telemedicine as part of national healthcare delivery policy based on this success story.

\section{Acknowledgments}

None.

\section{Funding}

None.

\section{Conflicts of interest}

The authors declare that there is no conflict of interest.

\section{References}

1. Brauchli K. Telemedicine for improving access to health care in resource-constrained areas. 2006.

2. Maryam A. Telemedicine and its Role in Revolutionizing Healthcare Delivery. The American Journal of Accountable Care. 2017;5(1).

3. Noor KAS, Anil P, Ashok P, et al. Telemedicine in Resource-Limited Setting: Narrative Synthesis of Evidence in Nepalese Context. Nepal Health Research Council, India. 2020.

4. Telemedicine opportunities and developments in Member States: Report on the second global survey on eHealth Global Observatory for eHealth series.

5. Eduardo O, Carolyn MC. Use of Information Technology to Improve the Quality of Health Care in the United States. Health Serv Res. 2003;38(2):xi-xxii.

6. Dan SW, Kaddu A. A meta-analysis of telemedicine success in Africa. J Pathol Inform. 2013;4:6 